\section{Incidence of Chronic Hepatitis after Epidemic of Infectious Hepatitis}

\author{
British Medical fournal, 1970, 4, 220
}

During the second world war the spread of infectious hepatitis reached pandemic proportions. It is thought that in Germany and the states occupied by that country more than 10 million people were affected (Kalk, 1957). In the Socialist Republic of Slovenia the first large postwar increase in the incidence of hepatitis was registered in 1958. From this time there was a gradual decline until 1966, when a dramatic increase occurred. This trend was reflected in the region served by the Celje Town Hospital, and during 1966 2,778 patients were admitted to the department of infectious diseases. We have attempted to assess the incidence of chronic hepatitis following this epidemic.

\section{Materials AND MethodS}

Of the 2,778 patients 1,429 were male and 1,349 female. The largest number ( 1,021 boys and 989 girls) were in the 5-15year age group.

The average period of stay in hospital was eight days only. A longer stay was not possible owing to the large number of patients and the limited supply of beds. Patients were discharged from hospital after the illness showed signs of regression. While in hospital they were subjected to a strict regimen of rest and dietetic measures, and were also given vitamin-B complex. Laevulose was used in cases where the serum bilirubin exceeded $5 \mathrm{mg} . / 100 \mathrm{ml}$., while prednisone was given to patients with a level of serum bilirubin above $10 \mathrm{mg}$. $/ 100 \mathrm{ml}$. We were not able to determine to what extent patients rested when at home.

Because of their short stay in hospital patients were carefully followed up during recovery; 255, however, did not attend for follow-up. In evaluating the severity of the illness we relied on two tests: in the acute phase we considered the serum alanine aminotransferase (S.G.P.T.) to be the most important; during the later phase special attention was paid to the thymol turbidity. If after one year the liver was enlarged and/or the thymol turbidity was greater than 5 units, liver biopsy was recommended. This was carried out on 38 patients- 31 females and 7 males.

\section{RESUltS}

Thirty-eight patients showed evidence of persisting liver damage after one year. Their thymol turbidity varied from 5 to 15.2 units, with an average of 8.2 . The value of the thymol turbidity did not correlate with the pathological process seen on liver biopsy. Seven biopsies were normal, 14 showed protracted hepatitis, 15 chronic persistent hepatitis, and 2 chronic active hepatitis (see Fig.). In one patient chronic hepatitis was associated with considerable steatosis. There was a single case of chronic active hepatitis which appeared to proceed to cirrhosis.

A girl aged 12 spent 20 days in hospital in 1966. Before her discharge the S.G.P.T. was within normal limits and thymol turbidity 9 units. When she was seen as an outpatient there was a slight increase in the S.G.P.T. but a decrease in thymol turbidity. In September 1967 she was readmitted with hepatic enlargement, S.G.P.T. 15 units, and thymol turbidity 5 units. Histological examination of the liver showed the appearances of chronic active hepatitis (see Fig.). A year later the liver was still enlarged and the spleen palpable three finger breadths below the costal margin, suggesting the development of cirrhosis.

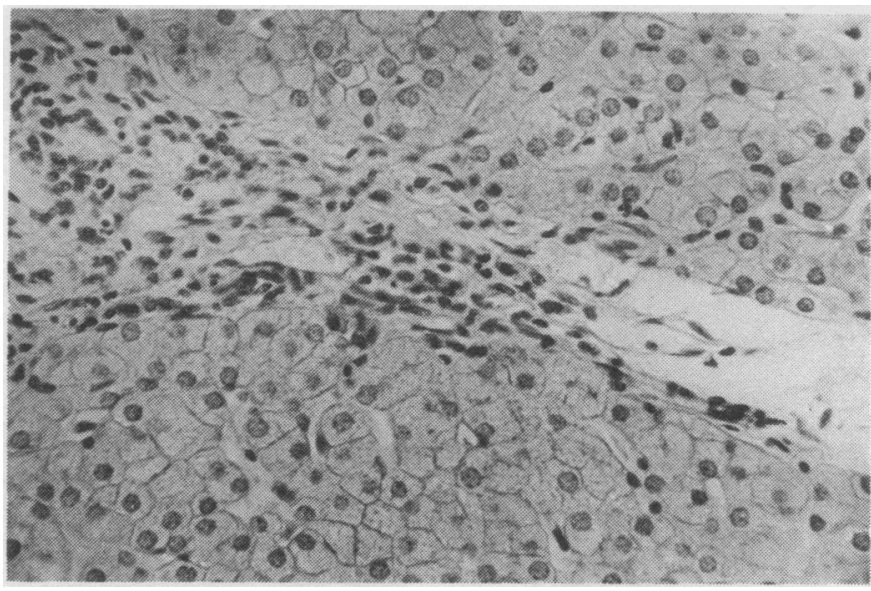

Histological appearance of the liver in a girl aged 12.

A cartographic survey showed that patients with the chronic forms of hepatitis did not occur in groups in a specific area of the Celje region which could point to a possible virulence of the causative agent.

\section{COMMENT}

Apart from the observations of Chalmers et al. (1951) dur ing the Korean war, a rest of at least six to eight weeks, and in protracted cases up to six months, is usually taken to represent the basis for recovery (Kalk, 1961). The diet is less significant. The prohibition of alcohol is very important; treatment with medicaments, however, is unreliable and often even harmful (Lilienfeld et al., 1953).

Because of the short stay in hospital during the epidemic, we were naturally interested in the possible transition of a large number of acute forms of epidemic hepatitis into a chronic illness. In fact only $31(1.1 \%)$ patients showed persisting liver damage. Gross and Herzog (1963) reported that 5 to $23.8 \%$ of patients with acute hepatitis developed chronic disease. Investigations made in the American army gave a figure of about $6 \%$ (Cullinan, 1952; Havens, 1962).

Though males were affected more often than females during the epidemic, it is interesting that chronic disease was four times more frequent among females. Lilienfeld et al. (1953) too reported that in their series of patients suffering from chronic hepatitis the proportion of female to male patients in the age group $15-19$ years was $4: 0.6$. Moreover, it should not be forgotten that epidemic hepatitis follows a much more severe course during pregnancy and during the menopause.

H. ZAVERSNIK, M.D.

S. Petrovic, M.D.

Celje General Hospital, Slovenia, Yugoslavia.

REFERENCES

Kalk, H. (1957). Verhandlungen der Deutschen Gesellschaft für innere Medizin, 63, 177.

Chalmers, T. C., et al. (1953). Journal of Clinical Investigation, 32, 559.

Kalk, H. (1961). Helvetica Medica Acta, 28, 382.

Lilienfeld, A. M., Bross, I. D. J., and Sartwell, P. E. (1953). American Fournal of Public Health, 43, 1085.

Gross, H., and Herzog, W. (1963). Münchener Medizinische Wochenschrift, $105,20$.

Cullinan, E. R. (1952). In History of the Second World War. Medicine and Pathology, ed. V. Z. Cope, p. 230. London. H.M.S.O.

Havens, W. P., jun. (1962). American fournal of Medicine, 32, 665. 